AIAA-98-4941

\title{
FACTORS RELATED TO SUCCESSFUL ENGINEERING TEAM DESIGN
}

\author{
Ronald H. Nowaczyk \\ Professor of Psychology, East Carolina University, Greenville, NC 27858 \\ $\&$ \\ Thomas A. Zang \\ Senior Member AIAA, Branch Head, Multidisciplinary Optimization Branch \\ NASA Langley Research Center, Hampton VA 23681
}

\begin{abstract}
$\underline{\text { Abstract }}$
The perceptions of a sample of 49 engineers and scientists from NASA Langley Research Center toward engineering design teams were evaluated. The respondents rated 60 team behaviors in terms of their relative importance for team success. They also completed a profile of their own perceptions of their strengths and weaknesses as team members. Behaviors related to team success are discussed in terms of those involving the organizational culture and commitment to the team and those dealing with internal team dynamics. The latter behaviors included the level and extent of debate and discussion regarding methods for completing the team task and the efficient use of team time to explore and discuss methodologies critical to the problem. Successful engineering teams may find their greatest challenges occurring during the early stages of their existence. In contrast to the prototypical business team, members on an engineering design share expertise and knowledge which allows them to deal with task issues sooner. However, discipline differences among team members can lead to conflicts regarding the best method or approach to solving the engineering problem.
\end{abstract}

\footnotetext{
This work was supported, in part, by NASA under NASA Contract No. NAS1-19480 while the first author was on sabbatical leave from Clemson University and in residence at the Institute for Computer Applications in Science and Engineering (ICASE), Hampton VA.

Copyright (C) 1998 by the American Institute of Aeronautics and Astronautics, Inc. No copyright is asserted in the United States under Title 17, U.S. Code. The U.S. Government has a royalty-free license to exercise all rights under the copyright claimed herein for Governmental Purposes. All other rights are reserved by the copyright owner.
}

The success or failure of a team depends on a number of factors. These include the ability of a team to develop and progress through a series of stages as it completes its task. ${ }^{2,4,6,7}$ The team must also satisfy several functions if it is to be successful. $^{3}$ Most of the research on team behavior has focused on the prototypical management team in industry or teams formed artificially in the laboratory solely for research purposes. To date, there has been little research on the functioning of teams of individuals working on an engineering or science problem.

A current view on the stages of team dynamics is a blend of contributions from earlier research., $2,4,6,7$ Morgan et al. have proposed that a team passes through two phases of "performing" the team task. $^{4}$ The first "performing" phase is preceded by the first team meeting, which is viewed as critical to the success of the team. Team norms and roles are often defined during the early team meetings. ${ }^{2}$ The two phases are separated by a transition stage when the team examines its progress and reevaluates its approach to the task or problem. This transition stage often occurs around the midpoint of the team's existence. ${ }^{2}$ The second performing phase is followed by task completion and the disbanding of the team.

Research has indicated that teams serve multiple functions. McGrath has identified three separate but interrelated team functions. ${ }^{3}$ The first function, which is obvious to most, is task production. Teams exist to complete their mission or task. The other two functions, member support and group well-being, can often be overlooked by individuals evaluating teams solely on the basis of task performance. Member support refers to the 
individual team members' perceptions that service on the team has been professionally or personally rewarding. Group well-being describes the social atmosphere that occurs within the team. A team that functions well in terms of group well-being includes members that feel that team communication and interactions were successful and that team members were able to fulfill specific team roles.

Little systematic research has been conducted on the effectiveness of teams of engineers and scientists working on specific engineering or scientific problems. The most definitive work on the performance of engineers and scientists was based on research prior to the recent emphasis on teams in industry and government. Pelz and Andrews identified eight creative tensions that they said contributed to a productive climate for scientists and engineers. ${ }^{5}$ Several of these creative tensions, as shown in Table 1, are relevant to successful team functioning.

Table 1. Creative tensions identified by Pelz \& Andrews that are relevant to team functioning. ${ }^{5}$

\begin{tabular}{|c|c|c|}
\hline Security & & Challenge \\
\hline & Tension A & \\
\hline $\begin{array}{l}\text { Effective scientists were intellectually } \\
\text { independent or self-reliant; they pursued } \\
\text { their own ideas and valued freedom... }\end{array}$ & & $\begin{array}{c}\text {.. But the did not avoid other people; } \\
\text { they and their colleagues interacted } \\
\text { vigorously }\end{array}$ \\
\hline & Tension B & \\
\hline $\begin{array}{c}\text { Among mature scientists, high performers } \\
\text { had greater self-confidence and an interest in } \\
\text { probing deeply... }\end{array}$ & & $\begin{array}{c}\text {... At the same time, effective older } \\
\text { scientists wanted to pioneer in broad } \\
\text { new areas }\end{array}$ \\
\hline & Tension C & \\
\hline $\begin{array}{l}\text { High performers named colleagues with } \\
\text { whom they shared similar sources of } \\
\text { stimulation (personal support) ... }\end{array}$ & & $\begin{array}{c}\text {.. but they differed from colleagues in } \\
\text { technical style and strategy (dither or } \\
\text { intellectual conflict) }\end{array}$ \\
\hline & Tension D & \\
\hline $\begin{array}{c}\text { R \& D teams were of greatest use to their } \\
\text { organization at that "group age" when interest } \\
\text { in narrow specialization had increased to a } \\
\text { medium level ... }\end{array}$ & t & $\begin{array}{c}\ldots \text { but interest in broad pioneering } \\
\text { had not yet disappeared }\end{array}$ \\
\hline $\begin{array}{c}\text { In older groups which retained vitality } \\
\text { the members preferred each other as } \\
\text { collaborators... }\end{array}$ & Tension E & $\begin{array}{c}\text {... yet their technical strategies differed } \\
\text { and they remained intellectually } \\
\text { combative }\end{array}$ \\
\hline $\begin{array}{l}\text { In departments having moderate coordination, } \\
\text { it seems likely that individual autonomy } \\
\text { permitted a search for the best solution ... }\end{array}$ & Tension F & $\begin{array}{c}\text {... to important problems faced by the } \\
\text { organization }\end{array}$ \\
\hline
\end{tabular}

These tensions are indicative, perhaps, of the inquisitive, probing characteristics associated with the scientific method. The challenges listed in Table 1 describe individuals who seek and appreciate the intellectual and technical interchange and challenges with others. These challenges may be especially important on multidisciplinary design teams where reliance on particular methodologies and identification of critical problem components may vary among disciplines. Some factors that are more likely to be present on multidisciplinary design teams than on teams composed of members from a single discipline are: a larger fraction of senior engineers (because of the need for disciplinary experts from several disciplines), a larger technical 
communication problem (because of different vocabularies of the different disciplines), a lengthier debating phase in the initial stages of the team, and often lesser priority on this interdisciplinary task from the management of the disciplinary homes of the team members than there would be for a task confined to a single discipline. Support for some of these challenges has been found in other studies. ${ }^{1,8}$

Successful task performance, therefore, may depend critically on how well the engineering design team encourages conflict and debate. Whereas, the prototypical management team is characterized by reaching consensus, one might hypothesize that for engineering design teams, consensus-building may be achieved only after considerable scientific and technical debate. And, in some instances, consensus may not be fully achieved, if the "correct" solution to a problem is the selection of a particular methodology over another and not the "blending" of methodologies.

The current study was designed to identify factors that are related to successful engineering design team performance. An engineering design team was defined as "a group of individuals working together toward a common goal, or solution that requires the sharing of expertise, knowledge, and ideas in a cooperative and interdependent fashion ... working on the design of an engineering process or product."

\section{Approach to the Problem}

\section{$\underline{\text { Participants }}$}

Volunteers were solicited from several branches from the Research and Technology Group (RTG), the Airframe Systems Program Office (ASPO) and the Internal Operations Group (IOG) at NASALangley Research Center (LaRC). The purpose of the study was described at several branch or team meetings and a packet containing the survey material was distributed to each attendee. (At LaRC, the branch is the smallest line organization; it typically consists of approximately 20 engineers.) The surveys were taken in 1997. Forty-nine of the 91 surveys distributed were returned via interoffice mail (a return rate of 54 percent). Respondents were asked not to include their names on any of the survey forms and participation was entirely voluntary.

\section{Survey \& Procedure}

There were three sections in the survey. The first described the purpose of the survey and provided the definition of a team as described in the introduction of this paper. The second section consisted of 60 statements." The first 20 statements described behaviors that involved the interactions of the team and its members with the organization. Examples of these external statements included "externally imposed time deadline is ambitious or challenging" and "job time allotted by supervisor for team service is appropriate." The remaining 40 statements described behaviors internal to the team and its interactions. Example statements included "the commitment of time to the team is uniform across team members", " team members are concerned about the feelings of others" and "the team adopts a shared vocabulary and set of methods for solving the problem." For each of these statements, the participant was asked to indicate the importance of the behavior to team success using a 5-point scale ("1" = "Not at all Important"; "3" = "Somewhat Important"; "5" = "Very Important"). The statements were constructed to tap into the major factors associated with team behavior. A number of them were also based on informal interviews with several supervisors at NASA-LaRC. These interviews focused on their perceptions of engineering team performance at LaRC.

The third section of the survey dealt with demographic information and a profile of the participant's own team behavior. The team member profile consisted of 20 statements. Participants were asked to rate each statement on a 6-point scale (from 1 = "very much unlike me" to $6=$ "very much like me") as it applied to the sentence stem "Others would view me as ..." Example statements included "willing to challenge the ideas proposed by others", "a person who is fact- and

\footnotetext{
"Copies of the survey may be obtained by contacting the author at nowaczykr@mail.ecu.edu. Statements used can also be found in a web-based report of this study under www.icase.edu (Research followed by Psychology links).
} 
information-oriented" and "one who strives to ensure that the team stays together." The statements were designed to capture the three team functions of task production, member support and group well-being.

\section{Results}

\section{Description of the Participants}

Seventy-four percent of the respondents were male and 26 percent were female. At least 25 of the respondents (51 percent of the sample) routinely deal with multidisciplinary issues. Eightyseven percent indicated that they had been in their profession 7 or more years and had also been at NASA for at least 7 years. Seventy-eight percent indicated that they were engineers, the majority in either aerospace or mechanical engineering. The remaining individuals were trained in a science discipline, many in either computer or mathematical science. The profile of these individuals was similar to the demographic data available at NASA-LaRC regarding their population of engineers and scientists in the RTG, ASPO and IOG. ${ }^{\dagger}$

\section{Factors Important to Team Success}

The mean ratings for the 60 behaviors ranged from a low of 1.87 to a high of 4.69 (on the 5-point scale). Twenty-one behaviors had mean ratings of 4.00 or higher (with $4=$ "important" and $5=$ "very important"). The mean importance ratings are shown for these items in Table 2 in descending order of importance separately for external and internal factors. Eight of the behaviors were related to external or organizational influences on a team. The other 13 behaviors dealt with internal team dynamics.

Three of the statements related to organizational influences (Behaviors 1, 2, and 6) highlight the need for the organization to provide the successful team with the required resources in terms of service time, staffing and budget. Pelz and Andrews' Tension F, which relates to organizational influence regarding the definition of the task or goal, is captured in several of the other behaviors on external influence. Statements 3, 7, and 8 deal with team goals, information, and the ability to alter or redefine those goals. Behavior 16 , that deals with the team's ability to internally alter its approach, also contributes to this creative tension. It is the respondents' perception that successful teams have organizational guidance in defining the team task, but that the team should also have freedom in dictating the approach to solution. Statement 5 addresses the member support function of teams. Team members feel professionally rewarded serving on successful teams. This is consistent with the underlying desire to be intellectually stimulated (see the creative tensions in Table 1). Statement 4 dealing with the technical competence of the team sponsor is consistent with other research reported by Pelz and Andrews which indicated that scientists felt most comfortable when their individual evaluations were conducted by someone with the technical knowledge and skills to understand their work.

A review of the internal factors reveals a pattern of behaviors among successful teams that is characterized by critical debate of scientific and engineering ideas and methodologies. There is evidence supporting Creative Tensions A, C, and $E$ from Table 1. It appears the participants expect dialogue and debate to occur during team meetings. Yet, the intellectual debate and potential conflict that appears to describe a successful engineering team (Statements 10, 11, $14,16,18$, and 21) is balanced by the recognition of added responsibilities on the part of team members (Statements 9, 13, 15, 17, 19 and 20). The "pioneering" interests of scientists and engineers described in Creative Tensions $B$ and $D$ of Table 1 appear to be captured in several team behaviors (Statements 15, 18, and 21). Lastly, there is support for the existence of a midpoint or transition stage during a successful team's life span (Statement 12).

\footnotetext{
${ }^{\dagger}$ The data were analyzed separately for individuals from these three groups and no significant differences were found among them. Therefore, the data discussed in subsequent sections have been combined across al groups.
} 
AIAA-98-4941

Table 2. Mean ratings and standard errors of the mean for the 21 behaviors viewed as important to team success.

Behavior

External Factors

1. Job time allotted by supervisor for team service is appropriate.

2. Assigned job priority to team service (as assigned by the supervisor) is commensurate with team responsibility and efforts.

3. Relevant information that is external to the team is available to the team.

4. Team sponsor is technically competent to evaluate team product.

5. Service on the team is professionally rewarding.

6. External resources (e.g., staff \& budget) are assigned to the team.

7. The product or task is well-defined before the team meets.

8. Team has the ability to alter or refine its goal or product.

Mean

S.E.M.

$4.69 \quad .07$

$4.58 \quad .09$

$4.43 \quad .10$

$4.41 \quad .12$

$4.33 \quad .12$

$4.32 \quad .13$

$4.23 \quad .13$

$4.14 \quad .12$

Internal Factors

9. There is a sense of "team responsibility" among the team members.

$4.64 \quad .09$

10. The team openly and critically debates various solutions to the problem based on their scientific and technical merits.

11. The team engages in "healthy" debate over various approaches to the problem or task early on.

12. The team experiences a point during its lifetime where it steps back and critically examines where it is going.

13. Not all team members may agree with the approach or method taken to completing the task, but are supportive of the "team decision."

14. Debate and critical evaluation of member ideas are encouraged.

15. Team members take the time to explain their ideas and methods so that team members learn from each other.

16. The team is able to redefine its approach to goal or task.

17. Team "team road map" is developed by the team.

$4.51 \quad .10$

$4.43 \quad .09$

$4.35 \quad .10$

$4.30 \quad .12$

$4.29 \quad .12$

$4.26 \quad .11$

$4.20 \quad .11$

$4.18 \quad .12$

18. A variety of engineering or science "tools" or "methodologies" are considered by $4.14 \quad .11$ the team.

19. The team leader is able to wear a variety of "hats" depending on the team's needs $4.12 \quad .12$ (e.g., from directive to facilitative).

20. The team uses time to understand the technical approaches and methods $\quad 4.02 \quad .12$ of its members.

21. The team spends time "exploring" new or potentially high-risk, high-payoff $\quad 4.00 \quad .11$ methods to completing its task.

\section{Profile of the Participants'Team Behaviors}

Participants described themselves in terms of behaviors that focused on the task production, member support, and group-well being functions. The behaviors were rated on a 6-point scale with lower values representing uncharacteristic behaviors (e.g., 1 = "very much unlike me) while larger values were descriptive of an individual's behavior (e.g., 6 = "very much like me" Table 3 lists the seven most descriptive team behaviors, with mean ratings from 4.79 to 5.13 ( $5=$ [behavior is] "like me"), and the three least descriptive behaviors, with mean ratings between 3.15 and 3.46 ( 3 = [behavior is "somewhat unlike me").

These behaviors describe individuals who are aware of the task production function of teams (Statements 1, 3, 4, and 7 in Table 3), as well as the group well-being function (Statements 2, 5 , 
and 6). The non-descriptive behaviors indicate that the respondents see conflict occurring on teams and are willing to shape the team's direction. They see their first priority as being task-focused, but appreciate the importance of maintaining team cohesiveness.

Table 3. Behaviors that most and least describe respondents.

\section{Most Descriptive Behaviors}

1. A person who is fact- and information-oriented.

2. One who is a "team-player."

3. A person who tends to be task-oriented.

4. A person who enjoys learning about the different approaches taken toward a problem by other team members.

5. A person tolerant of concerns of other team members.

6. A person who knows one's role and responsibilities on the team.

7. A person who will focus the team on the task.

\section{Least Descriptive Behaviors}

8. A person who feels conflict is not healthy on a team.

9. One who is careful not to influence the team's direction more than other team members.

10. One who is able to influence decision-makers beyond the team.

\section{Discussion}

This study speaks to two issues. The first deals with the behavior and performance of successful engineering teams within the context of team dynamics. The second, which is related to the first, focuses on the application of Pelz and Andrews' "creative tensions" to describe the behaviors and perceptions of engineers and scientists in a team environment.

\section{$\underline{\text { Team Dynamics }}$}

The findings from this study can be interpreted in terms of the three functions of team performance and the stages of team development. The three functions of a team include task production, member support, and group well-being. ${ }^{3}$ The engineering teams at NASA-LaRC place heavy emphasis on the task production function. This is not unexpected. The goal or task of an engineering team is an engineering design or solution to an engineering or science problem. Participants focused on the importance of task production in terms of critical and open debate and dialogue concerning engineering and science methodologies and solutions. (See Table 2.)

It was also apparent that engineers viewed group well-being as an essential component for successful teams. The participants valued the sense of "team responsibility" and indicated that it was important for team members to allow others to express their views and to be supportive of a team decision. There was less evidence that the participants felt the function of member support was as crucial to team success. It also appears that serving on a team provides professional rewards rather than career rewards. They suggested that successful teams allow the engineer or scientist to expand or increase his or her knowledge and skills within one's discipline.

The successful engineering team at NASA-LaRC does not fit the team conception proposed by Tuckman, which consisted of the sequential stages of "forming, storming, norming, performing, and adjourning." ${ }^{6,7}$ The successful engineering team exhibits a more complex pattern. First, there is support for Gersick's contention that teams experience a period in their existence where they examine their progress and reevaluate their work plan. ${ }^{2}$ Second, using the Morgan et al. model, the successful engineering team places more emphasis on the early phases of team development than the latter phases. ${ }^{4}$ Morgan, et al. proposed that teams have three distinct phases. The first and third are performance phases separated by a transition phase similar to Gersick's concept of a period of reevaluation. The first phase is characterized by considerable debate regarding the task and identification of member roles and team norms. This first phase also includes task work and performance. There is evidence that the successful engineering teams are those who have a productive first phase. Participants identified several behaviors that will lead to a productive first phase. These include critical and open debate, careful and reasoned 
explanations of ideas, and to some extent, a willingness to explore new approaches to the problem. The debate is described as being grounded in scientific and engineering principles.

A number of behaviors can work against a team being productive during this first phase. These include organizational influences such as externally imposed changes in team membership and insufficient time and organizational resources being devoted to the team to engage in the debate and discussion that seems to be so critical. The team may also contribute to its lack of success if it does not allow and expect participation from all of its members. Teams less likely to succeed may short circuit the debate and dialogue by allowing a single discipline, method, or subset of the team to dominate the team's direction. Lastly, teams that feel restricted in their choices or approaches to the problem or task may be less likely to succeed than those who feel that they have some freedom in defining the problem and solution.

Engineering design teams appear to differ from the prototypical business team on a few critical dimensions. The members on an engineering team will share some level of expertise (i.e., technical knowledge) among themselves that may not always be found on a business team where individuals come from unrelated disciplines. This shared expertise provides for a "shared mental model" among engineers and scientists, allowing for engineering teams to move more quickly into substantive debate and dialogue. The risk, in this instance, however, is that some individual team members assume that their mental model (i.e., knowledge base) is either superior or more complete than that of other team members. In those instances, an individual may likely feel that he or she possesses the solution to the problem at the exclusion of other team members.

On successful engineering teams, members may find themselves debating among a number of potential solutions, many of which have common principles or assumptions. The debate in these instances may be more focused and may involve subtle and technical distinctions not found in a business team. Hence, this phase of debate may be more critical to an engineering team's success than the "storming" stage associated with business teams. The debate and discussion in business teams may not be as task- or problem-rich as those for engineering teams.

The nature of the problem facing an engineering design team may also reveal an important difference from business teams. The respondents focused on the importance of task definition. Problems assigned to engineering teams may be viewed as well-defined problems. That is, the goal or solution to the engineering problem can be evaluated and tested. The set of methods for solving the problem may be known. While one "best" solution may not be definable, solutions can be rated relative to their success in meeting requirements. Engineering solutions can often be evaluated against a known set of criteria. Problems assigned to business teams may not be as objectively evaluated or tested. In some cases, the impact of the solution for the business team may not be known for a fairly long period of time.

These differences in problem definition and methods to solution result in the later phases of team dynamics involving task performance as being less of an issue for engineering teams. Engineering teams at NASA-LaRC appear to consist of individuals with the necessary expertise to solve the problem. The problem tends to be better defined than those for business teams. The main hurdle for engineering teams is the selection of the best or most appropriate methods for solving the problem. Once those methods are agreed upon, the team possesses the expertise and knowledge to work toward problem solution.

On the other hand, business teams may encounter greater difficulty in reaching a solution during the latter phases of task performance. The problem may not be as well-defined. The solution method may not be one with which all team members have some level of expertise and a shared mental model. And, lastly, the evaluation of the product may not be as clearly and objectively defined as that for the engineering team.

\section{Existence of "Creative Tensions"}

Six of the eight creative tensions for scientists and engineers were examined in this study. ${ }^{5}$ (See Table 1.) Each tension was described in terms of 
"security" and "challenge" components. The behaviors reported in successful engineering teams generally supported these tensions, especially in terms of "challenges." Pelz and Andrews had found that successful engineers and scientists interact vigorously, differ in technical style and strategy from each other, and remain intellectually combative. The importance of open and critical debate on successful teams certainly supports these challenges. The fact that successful teams were also likely to explore new methods fits with the challenges scientists and engineers prefer in terms of pioneering in broad new areas.

It should be noted that the team environment does threaten some of the "security" components of these tensions cherished by engineers and scientists. For instance, the team environment makes it more difficult for "effective scientists to be intellectually independent or self-reliant." Organizational control and influence is also a consideration. Pelz and Andrews, noted that scientists and engineers preferred moderate coordination that made it likely that an individual had the autonomy to search for the best solution. In a team environment, that autonomy may be extended to the team rather than the individual. This may explain why participants viewed successful teams as those that had the ability to alter or refine their goals and to develop their own "road map." The fact that the team sponsor should also be technically competent to evaluate the team product fits within this notion of effective oversight from the organization.

Therefore, it appears that the team environment offers the scientist or engineer the opportunity for dialogue and debate among colleagues that seems to be characteristic in many of the "challenge" components of Pelz and Andrews' creative tensions. The risk that is faced within the team environment, however, is that the "security" components may be restricted. While the intellectual debate and dialogue in a team environment are welcome, the effective engineer or scientist may feel uneasy about the loss of individual autonomy. The successful organization must work to make this transition from individual autonomy to team autonomy acceptable and palatable to the engineer or scientist. This may be accomplished through effective communication between the team and the team sponsor and effective leadership within the team so that the team is given as much autonomy and flexibility as possible in working toward its goal.

\section{Conclusions \& Future Work}

Several conclusions regarding successful engineering design teams can be offered. From an organizational perspective, a successful engineering design team is likely to:

- have a clearly defined task or problem provided by the organization;

- have the ability to alter or modify the problem as the team progresses; and,

- have adequate organizational support (i.e., staffing, resources, and sponsorship) and time to complete its task.

Within the team itself, successful engineering design teams should:

- engage in considerable debate and dialogue on the merits of various approaches to solution;

- $\quad$ seek out alternative methods and encourage equal participation from all its members; and,

- maintain a "balance" between the challenges and conflict of scientific debate (task production) and the appreciation for a cohesive team environment (group wellbeing).

These conclusions are consistent with those proposed in other reports examining the dynamics of multidisciplinary engineering design teams. ${ }^{1,8}$

Future work continues on two fronts. The first is the development of an assessment instrument that will enable an engineering design team to evaluate its progress as a team. The instrument which has already been pilot tested at NASA-LaRC examines team progress on a number of dimensions related to findings from this study. The second is a closer examination of the decision-making model that develops on engineering design teams. It is assumed that successful teams develop a "shared" mental model of the problem and its solution. That model develops from the individual models of the team members. The early debate and dialogue and subsequent work of the team shape this shared 
mental model. It is unlikely that the model is based simply on consensus or the averaging of all individual models. Rather, it is assumed that the direction of debate and dialogue and subsequent verification of test results through empirical verification allow the team to adopt features of some mental models and exclude others. In a multidisciplinary design environment, this shared mental model may be extremely critical and also slower in development. Given the different engineering approaches and considerations of team members from different disciplines, agreement on a team mental model (the cognitive schema that leads to the actual problem solution) may be more difficult.

\section{$\underline{\text { References }}$}

[1] J.-F. BARTHELEMY, K. M. JONES, R. J. SILCOX, W. A. SILVA, M. R. WASZAK \& R. H. NOWACZYK, Charting multidisciplinary team external dynamics using a systems thinking approach, Proceedings of the $7^{\text {th }}$ AIAA/USAF/NASA/ISSMO Symposium on Multidisciplinary Analysis and Optimization, (1998). Paper \# 98-4939.

[2] C. J. G. GERSICK, Time and transition in work teams: Toward a new model of group development, Academy of Management Journal, 31 (1988), pp. 9-41.

[3] J. E. McGRATH, Time matters in groups, in J. Gallegher, R. E. Kraut, \& C. Egido, (Eds.), Intellectual teamwork: Social and technological foundations of cooperative work,
(1990), Hillsdale, NJ: Erlbaum Press, pp. 2361.

[4] B. B. MORGAN, JR., A. S. GLICKMAN, E. A. WOODARD, A. S. BLAIWES, \& E. SALAS, Measurement of team behaviors in a Navy environment, Tech. Report No. NTSC TR-86014 (1986), Orlando, FL: Naval Training Systems Center.

[5] D. C. PELZ \& F. M. ANDREWS, Scientists in Organizations: Productive climates for research and development (Rev. Ed.), (1976), Ann Arbor, Ml: Institute for Social Research.

[6] B. W. TUCKMAN, Developmental sequence in small groups, Psychological Bulletin, 63 (1965), pp. 384-399.

[7] B. W. TUCKMAN \& M. C. JENSEN, Stages of small-group development revisited, Group \& Organizational Studies, 2 (1977), pp. 419427.

[8] M. R. WASZAK, J.-F. BARTHELEMY, K. M. JONES, R. J. SILCOX, W. A. SILVA, \& R. H. NOWACZYK, Modeling and analysis of multidiscipline research teams at NASA Langley Research Center: A systems thinking approach, Proceedings of the $7^{\text {th }}$ AIAA/USAF/NASA/ISSMO Symposium on Multidisciplinary Analysis and Optimization, (1998). Paper \# 98-49340. 